\title{
RESEARCH
}

Open Access

\section{Bone mineral density and bone microarchitecture in a cohort of patients with Erdheim-Chester Disease}

Tianhua He ${ }^{1+}$, Lijia Cui ${ }^{2+}$, Na Niư ${ }^{3}$, Fengdan Wang ${ }^{4}$, Huilei Miao ${ }^{1}$, Hao Zhao ${ }^{1}$, Xuemin Gao ${ }^{1}$, Chang Liu ${ }^{2}$, Fan Yu ${ }^{2}$, Yan Jiang ${ }^{2}$, Ou Wang ${ }^{2}$, Mei Li ${ }^{2}$, Xiaoping Xing ${ }^{2}$, Daobin Zhou' ${ }^{1}$, Jian $\mathrm{Li}^{1}$, Xinxin Cao ${ }^{1 *}$ (D) and Weibo Xia ${ }^{2 *}$

\begin{abstract}
Background: Erdheim-Chester Disease (ECD) is a rare type of non-Langerhans histiocytosis. Skeletal structures are affected in over 95\% ECD patients. Due to the lack of proper imaging assessment tools, the alteration of bone microarchitecture in ECD has not been well studied. High-resolution peripheral quantitative computed tomography (HR-pQCT) is a newly developed assessment of bone mineral density and bone microarchitecture.

Methods: We performed a cross-sectional study with 13 patients diagnosed with ECD in Peking Union Medical College Hospital between October 2018 and June 2019. The diagnosis of ECD was based on typical pathological findings in the context of appropriate clinical and radiological manifestations. Bone geometry, volumetric bone mineral density and bone microarchitecture of those ECD patients were assessed using HR-pQCT at the nondominant distal radius and distal tibia. Those HR-pQCT parameters were then compared to an ongoing populationbased database of HR-pQCT for Mainland Chinese.

Results: As a result, remarkable heterogeneity of osteosclerosis in the HR-pQCT images was found in ECD patients, ranging from apparent normal structure, scattered thickening of trabecula, to homogenous consolidation. In terms of quantitative measurements, total volumetric BMD $\left(383.50 \mathrm{mg} / \mathrm{cm}^{3}, 1.352\right.$ times of normal mean, $\left.p=0.023\right)$ of the tibia differed significantly in ECD patients, due to the increased trabecular volumetric BMD $\left(291 \mathrm{mg} / \mathrm{cm}^{3}, 2.058\right.$ times of normal mean, $p=0.003$ ). The increased trabecular volumetric BMD of tibia was associated with remarkably increased number of trabecula $(1.7 / \mathrm{mm}, 1.455$ times of normal mean, $p=0.002)$ and increased thickness of trabecula $(0.37 \mathrm{~mm}, 1.466$ times of normal mean, $p=0.003)$. These differences could be due to the existence of dense bone interposed in the trabecula.

Conclusion: This study is the first to assess the volumetric bone mineral density and bone microstructure with HRpQCT in a cohort of ECD patients and indicated that the application of HR-pQCT may help to reveal the nature of bone lesions in the disease.
\end{abstract}

Keywords: Non-Langerhans histiocytosis, HR-pQCT, Chinese

\footnotetext{
* Correspondence: CaoXinXin@pumch.cn; xiaweibo8301@163.com

${ }^{\dagger}$ Tianhua He and Lijia Cui contributed equally to this work.

'Department of Hematology, Peking Union Medical College Hospital,

Chinese Academy of Medical Sciences, Beijing 100730, China

${ }^{2}$ Department of Endocrinology, Key Laboratory of Endocrinology, Ministry of

Health, Peking Union Medical College Hospital, Chinese Academy of Medical

Sciences, Beijing 100730, China

Full list of author information is available at the end of the article
}

(c) The Author(s). 2020 Open Access This article is licensed under a Creative Commons Attribution 4.0 International License, which permits use, sharing, adaptation, distribution and reproduction in any medium or format, as long as you give appropriate credit to the original author(s) and the source, provide a link to the Creative Commons licence, and indicate if changes were made. The images or other third party material in this article are included in the article's Creative Commons licence, unless indicated otherwise in a credit line to the material. If material is not included in the article's Creative Commons licence and your intended use is not permitted by statutory regulation or exceeds the permitted use, you will need to obtain permission directly from the copyright holder. To view a copy of this licence, visit http://creativecommons.org/licenses/by/4.0/ The Creative Commons Public Domain Dedication waiver (http://creativecommons.org/publicdomain/zero/1.0/) applies to the data made available in this article, unless otherwise stated in a credit line to the data. 


\section{Background}

Erdheim-Chester Disease (ECD) is a rare type of nonLangerhans histiocytosis, characterized by multi-system infiltration with lipid-laden foamy histiocytes positive of CD68 and negative of CD1a [1, 2]. Over 1500 cases of ECD have been reported worldwide [3]. Skeletal structures are affected in over 95\% ECD patients [4], while extraosseous lesions have also been reported, including of the cardiovascular system, retroperitoneum, central nervous system (CNS), and skin involvement. Typical skeletal manifestation of ECD is bilateral osteosclerosis in the metaphyseal and diaphyseal regions [4]. Several imaging techniques have been used to evaluate the bone involvement of ECD. Bone scintigraphy of ECD patients may show pathological uptake in long bones due to cortical osteosclerosis [2]; positron emission tomographycomputed tomography (PET-CT) has advantages in showing the extent and activity of ECD lesions, and the therapeutic response to BRAF inhibitor, MEK inhibitor and interferon- $\alpha$ [3, 5-9]; computed tomography (CT) and magnetic resonance imaging (MRI) may help imageguided biopsy for ECD diagnosis [1]. However, due to the lack of proper imaging assessment tools, the alteration of bone microarchitecture in ECD has not been well studied.

High-resolution peripheral quantitative computed tomography (HR-pQCT) is a recently developed threedimensional imaging tool that assesses volumetric bone mineral density (vBMD) and bone microarchitecture in vivo in peripheral skeletal sites [10]. HR-pQCT works by scanning the peripheral bones (mainly tibia and radius), automatically recognizing and separating the bone cortex and trabecula, obtaining multiple bone microarchitecture parameters by direct measurement and mathematical modeling, and reconstructing three-dimensional skeletal images for visualization [11]. HR-pQCT is superior to conventional dual-energy X-ray absorptiometry (DXA) in the following aspects: (1) HR-pQCT examines the three-dimensional volumetric bone mineral density (BMD) while DXA assesses the two-dimensional areal BM; (2) HR-pQCT provides a higher resolution to differentiate between bone cortex and trabecula than DXA; (3) HR-pQCT assesses bone microarchitecture in a clear view. In recent years, HRpQCT has already been applied in examining the bone quality in metabolic bone diseases including osteoporosis $[12,13]$, hereditary hypophosphatemic osteomalacia [14], vitamin-D dependent rickets [11], and hematological diseases including monoclonal gammopathy of undetermined significance (MGUS) [15]. The skeletal involvement in ECD is severe and common, and the nature of bone lesions in the disease remains unknown. Due to the rarity of this disease, HR-pQCT has never been applied in ECD before. In this study, we performed a cross-sectional study of HR-pQCT in 13 ECD patients in our center to examine their changes in vBMD and bone microarchitecture.

\section{Methods}

\section{Patients enrolled}

Thirteen patients diagnosed with ECD in Peking Union Medical College Hospital (PUMCH, Beijing, China) were enrolled in the study between October 2018 and June 2019. The diagnosis of ECD was based on typical pathological findings in the context of appropriate clinical and radiological manifestations [4]. Patients were excluded if they were also diagnosed with autoimmune diseases, osteoporosis, other osteosclerotic diseases, other malignancies, bone fractures of radius or tibia, or have been treated with glucocorticoids in the past 1 year.

Demographic characteristics and clinical manifestations were documented at the time of enrollment, and HR-pQCT was completed within 2 weeks. For newly diagnosed patients, HR-pQCT was done before treatment was initiated. Treatment-experienced patients were treated with high-dose interferon- $\alpha$ therapy, defined as 600 or 900 MIU three times per week.

Ethics approval was obtained for the study from the institutional board. All participants were informed both in person by $\mathrm{TH}$, and written informed consents were obtained. The study was performed in accordance with the ethical standards of the 1964 Declaration of Helsinki and its later amendments.

\section{Evaluation and definition}

Multisystem involvement was confirmed by either clinical symptoms or radiological findings. Cardiovascular system involvements, valve abnormalities or periaortic fibrosis, were evaluated with cardiac MRI or CT, or echocardiograph. CT scans of the chest and abdomen were also applied for assessing retroperitoneal tissue fibrosis ("hairy kidney") and pulmonary involvement. For central nervous system involvement, we introduced MRI for patients with related symptoms. PET-CT has also been performed for evaluating whole-body multisystem involvement.

\section{High-resolution peripheral quantitative computed tomography (HR-pQCT)}

Bone geometry, volumetric bone mineral density (vBMD) and bone microarchitecture were assessed using HR-pQCT (XtremeCT II; Scanco Medical, Zurich, Switzerland) at the non-dominant distal radius and distal tibia. Each measurement was initiated at $9.5 \mathrm{~mm}$ and $22.5 \mathrm{~mm}$ from the mid-endplate at the radius and tibia, respectively. One hundred sixty-eight parallel slices were obtained in the axial direction, providing images with an isotopic image voxel size of $82 \mu \mathrm{m}$. The image quality was assessed by an experienced technician using the 5step scale, and the images with quality worse than grade 3 were excluded from the analysis [16].

The contour between cortex and trabecula was defined automatically using the manufacturer's standard software 
with manually assistance by one of the authors $(\mathrm{TH})$. The following measurements were calculated: 1) Bone geometrical measures including total (Tt.Ar), cortical (Ct.Ar) and trabecular (Tb.Ar) areas $\left.\left(\mathrm{mm}^{2}\right), 2\right)$ vBMD (mg hydroxyapatite $/ \mathrm{cm}^{3}$ ) of the entire cross section (Tt.vBMD), cortical section (Ct.vBMD) and trabecular section (Tb.vBMD), and 3) microarchitectural parameters including trabecular bone volume to tissue volume fraction (BV/ TV), trabecular number (Tb.N, mm-1), trabecular thickness (Tb.Th, $\mathrm{mm}$ ), trabecular separation (Tb.Sp, $\mathrm{mm}$ ), standard deviation of $1 / \mathrm{Tb} . \mathrm{N}$ to represent trabecular network inhomogeneity (Tb.1/N.SD, mm), cortical thickness (Cr.Th, mm) and cortical porosity (Ct.Po, \%).

\section{Other bone imaging}

All patients had the ${ }^{18}$ F-Fluorodeoxyglucose (FDG) positron emission tomography (PET) scan and $99 \mathrm{~m}$ methylene diphosphonate ( $\left.{ }^{99 \mathrm{~m}} \mathrm{Tc}-\mathrm{MDP}\right)$ bone scintigraphy for a better definition of the range of bone lesions. We also documented X-rays of affected regions as additional evaluations. One patient has also taken MRI of the affected ankle to determine the nature of bone lesions.

\section{Data processing and statistics}

All statistical analyses were performed using $R$ ( $R$ version 3.6.0, 2019-04-26, 2019 The R Foundation for Statistical Computing Platform) [17]. Age-, gender- and site specific distributions were derived from generalized additive models for location, scale, and shape (GAMLSS) with age as the only explanatory variable, based on an ongoing population-based study of HR-pQCT for Mainland Chinese $[18,19]$ (Supplementary Table 1). For each patient, Zscores of each measurement were derived from the fitted distribution models, as well as the reference mean of the healthy population. All measurements of HR-pQCT were compared with and adjusted to the corresponding reference normal mean. One sample $t$-test was performed comparing each relative value to 1 , and $p$ value $<0.05$ was considered to be statistically significant.

\section{Results}

Patients

Thirteen ECD patients were enrolled in the study (Table 1), with a median age of 47 years (range 19-62) and an even distribution of males and females. One patient was ECD overlapped with Langerhans cell histiocytosis (LCH). Seven

Table 1 Demographic features of 13 ECD patients

\begin{tabular}{|c|c|c|c|c|c|c|c|c|}
\hline ID & Sex/ Age & Organ involvement & Bone scintigraphy & Biopsy position & $\begin{array}{l}\text { BRAF-PCR/ } \\
\text { immuno- } \\
\text { histochemistry }\end{array}$ & $\begin{array}{l}\text { Disease } \\
\text { duration } \\
\text { (months) }\end{array}$ & $\begin{array}{l}\text { Treatment } \\
\text { history }\end{array}$ & $\begin{array}{l}\text { Regimen/ } \\
\text { Treatment } \\
\text { duration } \\
\text { (months) }\end{array}$ \\
\hline LJ004 & $M / 46$ & $\begin{array}{l}\text { Bone, heart, } \\
\text { vasculature, } \\
\text { retroperitoneal, } \\
\text { peritoneum }\end{array}$ & Typical uptake & Diaphragm & $(-) / N A$ & 19 & No & $\backslash$ \\
\hline LJ008 & $F / 49$ & $\begin{array}{l}\text { Bone, CNS, heart, } \\
\text { vasculature }\end{array}$ & Typical uptake & Foramen magnum & NA/NA & 48 & No & 1 \\
\hline LJ013 & $\mathrm{F} / 30$ & Bone, CNS, pancreas & Typical uptake & Sellar region & $\mathrm{NA} /(-)$ & 74 & No & 1 \\
\hline LJ019 & M/19 & $\begin{array}{l}\text { Bone, lungs, } \\
\text { retroperitoneal, pleura, } \\
\text { exophthalmos }\end{array}$ & Typical uptake & Right lung & $(+) / N A$ & 22 & Yes & IFN/9 \\
\hline LJ020 & $M / 54$ & Bone, exophthalmos & Typical uptake & Periorbital region & NA/NA & 39 & No & 1 \\
\hline LJ023 & $F / 57$ & Bone, lungs & Typical uptake & Tibia & $(+) /(+)$ & 63 & Yes & IFN/15 \\
\hline LJ024 & $F / 26$ & $\begin{array}{l}\text { Bone, CNS, thymus, } \\
\text { exophthalmos }\end{array}$ & Typical uptake & Periorbital region & $(+) /(+)$ & 246 & Yes & IFN/24 \\
\hline LJ025 & $F / 53$ & Bone, exophthalmos & Typical uptake & Periorbital region & NA/NA & 49 & No & $\backslash$ \\
\hline LJ033 & M/49 & $\begin{array}{l}\text { Bone, pleura, } \\
\text { nerve roots }\end{array}$ & Typical uptake & Pleura, intraspinal mass & $(+) / \mathrm{NA}$ & 71 & Yes & IFN/46 \\
\hline LJ038 & $M / 62$ & $\begin{array}{l}\text { Bone, vasculature, } \\
\text { retroperitoneal, } \\
\text { pericardium }\end{array}$ & Typical uptake & Pericardium & $(+) /(+)$ & 34 & Yes & IFN/30 \\
\hline LJ043 & $F / 47$ & $\begin{array}{l}\text { Bone, vasculature, } \\
\text { retroperitoneal, } \\
\text { exophthalmos }\end{array}$ & Typical uptake & Periorbital region & $\mathrm{NA} /(-)$ & 138 & No & 1 \\
\hline LJ045 & M & $\begin{array}{l}\text { Bone, CNS, lungs, } \\
\text { vasculature, gingiva }\end{array}$ & Typical uptake & Gingiva & $(-) / N A$ & 255 & Yes & IFN/35 \\
\hline LJ047 & M & Bone & $\begin{array}{l}\text { High uptake within } \\
\text { Distal right fibula }\end{array}$ & Right fibula & NA/NA & 4 & No & $\backslash$ \\
\hline
\end{tabular}


were treatment-naïve patients, of which one patient had repeated HR-pQCT assessment after a 6-month treatment. The other treatment experienced patients had intermittent high-dose interferon injection for 15-46 months. BRAF V600E mutation was positive in five out of nine patients tested by either PCR or immunohistochemical approach.

All patients enrolled had bone involvement confirmed by PET-CT or bone scintigraphy, and the sites of bone lesions were listed in Table 1.

\section{Geometry, vBMD, and microarchitecture by HR-pQCT}

Bone geometry, volumetric BMD, microarchitecture measurements obtained by HR-pQCT were shown in Table 2 and Supplementary Table 2. Tt.vBMD (383.50 $\mathrm{mg} / \mathrm{cm}^{3}, 1.352$ times of normal mean, $p=0.023$ ) of the tibia differed significantly in ECD patients, attributing to the increased Tb.vBMD $\left(291 \mathrm{mg} / \mathrm{cm}^{3}, 2.058\right.$ times of normal mean, $p=0.003)$. The increased Tb.vBMD of tibia was associated with remarkably increased number of trabecula (Tb.N, 1.7/mm, 1.455 times of normal mean, $p=0.002$ ) and increased thickness of trabecula (Tb.Th, $0.37 \mathrm{~mm}, 1.466$ times of normal mean, $\mathrm{p}=$ 0.003). There were no significant differences in geometric features (Tt.Ar, Ct.Ar, or Tb.Ar) or microachitectural features in the cortex of tibia (Ct.Th or Ct.Po). And most HR-pQCT parameters in the radius showed no significant difference.

\section{Patterns of bone lesions by HR-pQCT image}

As shown in Fig. 1, great heterogeneity in bone microarchitecture was found in HR-pQCT images in ECD patients. Some ECD patients presented scattered thickening of trabecula (LJ008, LJ019, LJ024, LJ033 and LJ038), some presented homogeneous osteosclerosis (LJ020, LJ023 and LJ045), and others showed apparently normal structure. Besides, tibia was involved in most ECD patients (Fig. 1) with more evident distortion of bone structures, while radius was involved in less of them.

\section{Comparison of HR-pQCT with other bone imaging}

Figure 2 presented the bone lesions of one representative patient (LJ008) evaluated by bone scintigraphy, MRI, HR-pQCT, and PET-CT. Bone scintigraphy and PETCT demonstrated characteristic bilateral distal tibia osteosclerosis (Fig. 2A and B). The MRI of left ankle revealed a localized lesion, with heterogenic low signal on T1- and T2-weighted image, resembling corticalized loci within the trabecular regions (Fig. 2F). Comparing MRI cross-sectional image (Fig. 2E) with HR-pQCT (Fig. 2C), those typical bone lesions

Table 2 HR-pQCT measurements in 13 ECD patients

\begin{tabular}{|c|c|c|c|c|c|c|}
\hline & \multicolumn{3}{|l|}{ Tibia } & \multicolumn{3}{|l|}{ Radius } \\
\hline & $\begin{array}{l}\text { Mean } \pm \text { standard } \\
\text { deviation }\end{array}$ & $\begin{array}{l}\text { Mean of } \\
\text { adjusted value* }\end{array}$ & $P$-value ${ }^{* *}$ & $\begin{array}{l}\text { Mean } \pm \text { standard } \\
\text { deviation }\end{array}$ & $\begin{array}{l}\text { Mean of } \\
\text { adjusted value* }\end{array}$ & P-value ${ }^{* *}$ \\
\hline \multicolumn{7}{|l|}{ Bone geometry } \\
\hline Total area $(\mathrm{mm} 2)$ & $722.39 \pm 81.79$ & $1.003 \pm 0.104$ & 0.924 & $286.64 \pm 61.63$ & $0.992 \pm 0.170$ & 0.859 \\
\hline Cortical area (mm2) & $115.01 \pm 36.79$ & $0.887 \pm 0.363$ & 0.273 & $60.75 \pm 11.72$ & $0.871 \pm 0.204$ & 0.032 \\
\hline Trabecular area (mm2) & $612.07 \pm 81.88$ & $1.029 \pm 0.104$ & 0.320 & $229.63 \pm 58.64$ & $1.029 \pm 0.199$ & 0.599 \\
\hline \multicolumn{7}{|l|}{ Bone mineral density } \\
\hline Total BMD (mg/cm3) & $383.5 \pm 127.69$ & $1.352 \pm 0.521$ & 0.023 & $367.96 \pm 120.92$ & $1.097 \pm 0.399$ & 0.391 \\
\hline Trabecular BMD (mg/cm3) & $291.87 \pm 146.46$ & $2.058 \pm 1.165$ & 0.003 & $223.15 \pm 150.06$ & $1.529 \pm 1.246$ & 0.139 \\
\hline Cortical BMD (mg/cm3) & $886.37 \pm 83.37$ & $0.952 \pm 0.085$ & 0.052 & $887.94 \pm 76.93$ & $0.955 \pm 0.080$ & 0.055 \\
\hline \multicolumn{7}{|l|}{ Microarchitecture measurements } \\
\hline Trabecular BV/TV & $0.41 \pm 0.2$ & $1.876 \pm 1.005$ & 0.004 & $0.33 \pm 0.23$ & $1.570 \pm 1.307$ & 0.129 \\
\hline Trabecular number (1/mm) & $1.7 \pm 0.53$ & $1.455 \pm 0.469$ & 0.002 & $1.58 \pm 0.54$ & $1.154 \pm 0.392$ & 0.170 \\
\hline Trabecular thickness (mm) & $0.37 \pm 0.12$ & $1.466 \pm 0.509$ & 0.003 & $0.31 \pm 0.17$ & $1.361 \pm 0.783$ & 0.110 \\
\hline Trabecular spacing (mm) & $0.60 \pm 0.20$ & $0.865 \pm 0.293$ & 0.109 & $0.68 \pm 0.36$ & $0.977 \pm 0.464$ & 0.858 \\
\hline $\begin{array}{l}\text { Standard deviation of 1/ } \\
\text { trabecular number }\end{array}$ & $0.25 \pm 0.09$ & $0.763 \pm 0.274$ & 0.005 & $0.30 \pm 0.22$ & $1.124 \pm 0.721$ & 0.540 \\
\hline Cortical thickness (mm) & $1.30 \pm 0.42$ & $0.909 \pm 0.343$ & 0.348 & $1.03 \pm 0.20$ & $0.887 \pm 0.189$ & 0.041 \\
\hline Cortical porosity (\%) & $0.02 \pm 0.02$ & $1.346 \pm 0.904$ & 0.180 & $0.01 \pm 0.01$ & $1.854 \pm 2.312$ & 0.196 \\
\hline
\end{tabular}

${ }^{a}$ The adjusted value was the quotient of the measurements and that of the reference normal mean, which derived from an ongoing population-based study of HR-pQCT in Chinese population [19]. Details of fitted distribution model was listed in supplementary document

b p-value: one sample t-test

Abbreviations: BMD, bone mineral density; BV/TV, bone volume to tissue volume fraction; 

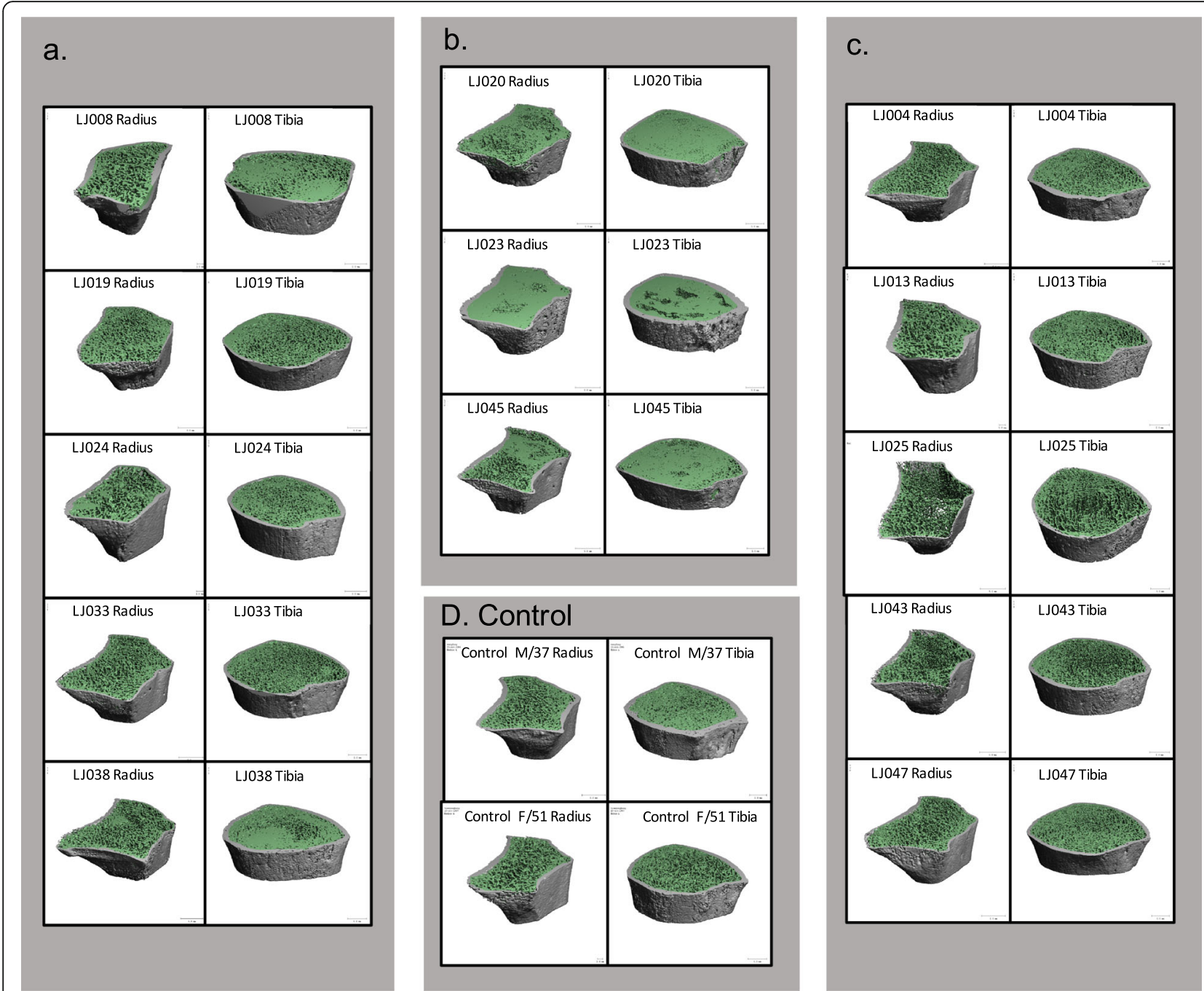

Fig. 1 HR-pQCT three-dimensional images of 13 ECD patients at distal radius (R) and tibia (T), grouped by their bone microarchitecture features: a scattered trabecular thickness, $\mathbf{b}$ homogeneously osteosclerosis, or $\mathbf{c}$ apparently normal structures. $\mathbf{d} \mathrm{HR}$-pQCT three-dimensional images of healthy controls

showed an infiltration of dense mass with the original trabecular networking spared.

\section{HR-pQCT measurements before and after treatment}

HR-pQCT was repeated in one ECD patient (LJ004) before and after interferon treatment for 6 months. As shown in Table 3, no significant changes in volumetric BMD and microarchitecture measurements were found before and after treatment.

\section{Discussion}

This study is the first to assess the bone microstructure with HR-pQCT in a cohort of patients diagnosed with ECD. Our data revealed great heterogeneity in bone microarchitecture alteration within trabecular region, from apparent normal structure, scattered thickening of trabecula, to homogeneous consolidation of trabecula. In terms of quantitative measurements of bone geometry, vBMD, and microarchitecture, ECD patients had significantly increased Tb.vBMD, Tb.Th, Tb.N, and BV/TV in the distal tibia, which could be due to the existence of dense bone interposed in the trabecula.

Though the etiology of ECD remains unclear, ECD is now believed to be a clonal disorder marked by frequent hyper-activation of mitogen-activated protein kinase signaling [20]. The mixed distribution of dense and normal bones may be attributed to the active bone resorption and its secondary osteogenesis, due to an altered inflammatory milieu, as shown in Fig. 2E and F. MRI further suggested bone infarction with secondary osteogenesis, showing serpiginous peripheral low $\mathrm{T} 1$ and high $\mathrm{T} 2$ signal due to granulation or sclerosis, and central high T1 and low T2 signal of bone marrow. The occurrence of bone infarction can be attributed to histiocyte 
a

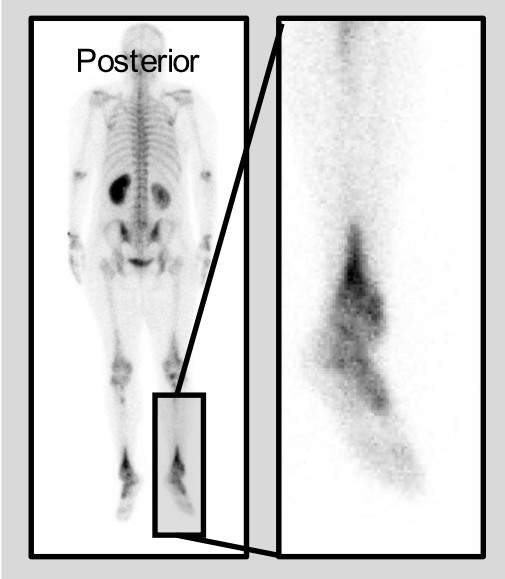

C

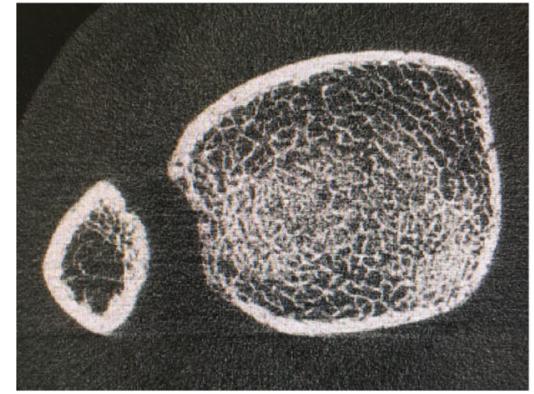

e

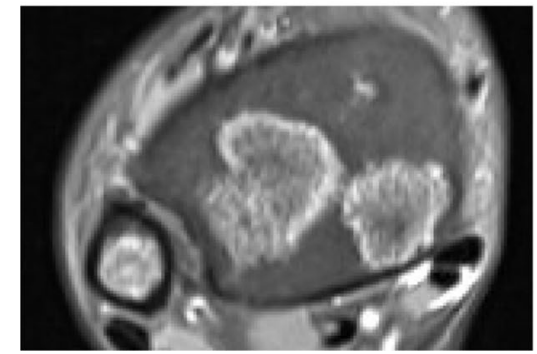

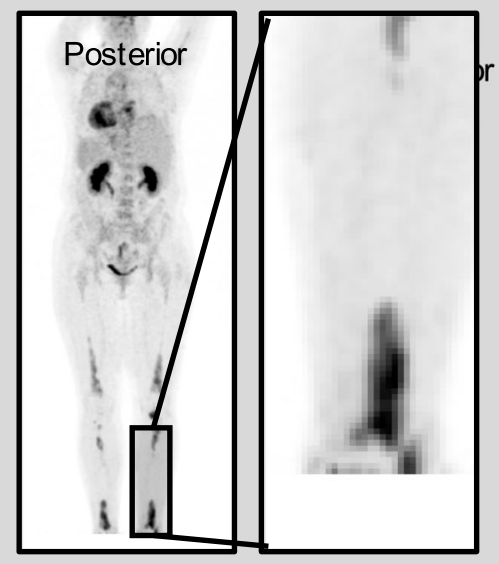

b

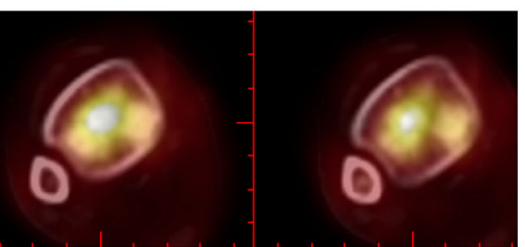

d

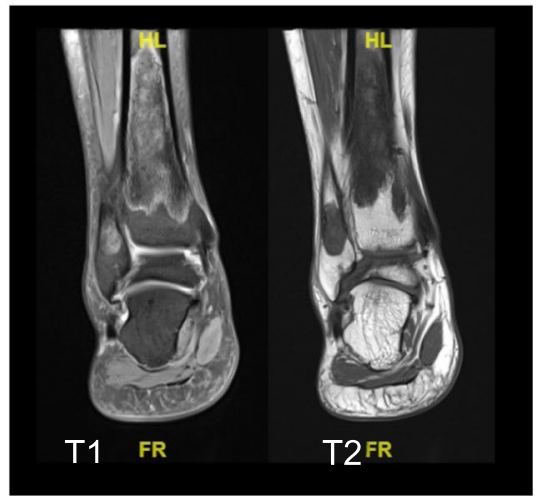

$f$

Fig. 2 Images of bone scintigraphy, positron emission tomography-computed tomography (PET-CT), HR-pQCT and Magnetic Resonance Imaging. (MRI) in one representative treatment-naïve ECD patients (L008). a Bone scintigraphy showed bilateral symmetric uptake at the distal tibial region. b PET-CT showed abnormal uptake at the same tibial region. c HR-pQCT revealed localized structural alteration of trabeculae network in right tibia. $\mathbf{d}$ Cross-sectional view of PET-CT showed increase of uptake in tibia, where bone lesions existed, reaching a SUV maximum of 5. e and f MRI of affected left ankle showed localized heterogeneous low T1- and T2-signal, resembling that of cortex

infiltration and alteration of microenvironment within bone marrow. This can be a slow process with necrosis, resorption, formation and ossification happening simultaneously, which partially explained why the osteosclerosis extent shown in $\mathrm{pQCT}$ were not strictly associated with the duration of disease (Fig. 1) nor with the duration of treatment (Table 3). Previous reported ECD cases with bone biopsy further confirmed thickened trabeculae with osteosclerosis and increased bone marrow cellularity, which was related to infiltration of foamy histiocytes [21]. Another review of pathological findings of ECD affected bones also found replacement of normal bone marrow with fibrosis and sclerosis of varied degree, and reactive bone formation was commonly seen [22]. Further studies with long-term follow-up and repeated evaluation of the morphology evolutions by MRI, microarchitecture alterations by HR-pQCT, and metabolic activities by bone scintigraphy and PET/CT, may help in understanding the nature of bone lesions in ECD.

We found different patterns of bone microarchitecture alteration among ECD patients, and such changes were predominantly within trabecular regions, while cortical regions remain spared. Our 3D microarchitecture helped to differentiate the thickened marginal trabeculae with the cortex, especially for patients with acentric and multiple lesions. Therefore, classically known bone lesions 
Table 3 Compare HR-pQCT measurements pre- and six-month post- treatment of one representative patient (LJ004)

\begin{tabular}{|c|c|c|c|c|}
\hline & Pre-Tx Tibia & Post-Tx Tibia & Pre-Tx Radius & Post-Tx Radius \\
\hline \multicolumn{5}{|l|}{ Geometric features } \\
\hline Total area (mm2) & 784.8 & 776.4 & 335.8 & 301.4 \\
\hline Cortical area (mm2) & 147.2 & 146.2 & 72.9 & 76.1 \\
\hline Trabecular area (mm2) & 643.3 & 635.9 & 267.1 & 229.1 \\
\hline \multicolumn{5}{|l|}{ Volumetric BMD } \\
\hline Total BMD (mg/cm3) & 350.7 & 361.1 & 310.1 & 337.7 \\
\hline Trabecular BMD (mg/cm3) & 223.7 & 228.5 & 145 & 134.8 \\
\hline Cortical BMD (mg/cm3) & 911.3 & 944.8 & 930.2 & 960.6 \\
\hline \multicolumn{5}{|l|}{ Microarchitecture measurements } \\
\hline Trabecular BV/TV & 0.326 & 0.328 & 0.204 & 0.189 \\
\hline Trabecular number (1/mm) & 1.885 & 1.462 & 1.467 & 1.516 \\
\hline Trabecular thickness (mm) & 0.305 & 0.322 & 0.216 & 0.216 \\
\hline Trabecular spacing (mm) & 0.536 & 0.696 & 0.647 & 0.637 \\
\hline Standard deviation of $1 /$ trabecular number & 0.22 & 0.293 & 0.228 & 0.23 \\
\hline Cortical thickness (mm) & 1.58 & 1.616 & 1.123 & 1.247 \\
\hline Cortical porosity (\%) & 0.01 & 0.01 & 0.007 & 0.004 \\
\hline
\end{tabular}

Abbreviations: BMD, bone mineral density; BV/TV, bone volume to tissue volume fraction;

of ECD with cortical thickness and sclerosis may result from insufficient resolution and misread. Our findings from HR-pQCT was consistent with pathological findings of replacement of normal bone marrow with fibrosis and sclerosis [22].

As the clinical spectrum of ECD ranges from asymptomatic to multi-organ lesions, we think that the different patterns and extent of bone microarchitecture alteration could be attributed to the different stages of the disease. Dion and colleagues have reported similar findings in 11 ECD patients based on X-ray, as $65 \%$ of the patients presented heterogeneous osteosclerosis and $35 \%$ of them presented homogenous osteosclerosis [23].

The phenomenon of scattered thickening of trabeculae is very rarely seen in other bone diseases. A similar pattern has only been reported in autosomal dominant osteopetrosis (ADO), which was explained as a random distribution of old and fragile bones along the skeleton by Arruda and colleagues [24]. As for osteoid osteoma, a benign tumor with featured bone formation, Rolvein et al. applied HR-pQCT to image a few cases with intraarticular osteoid osteoma and found typical subchondral nidus with central calcification and surrounding reactive bone formation [25]. Osteosarcoma is characterized by direct formation of immature bone by the tumor cells. HR-pQCT scan of murine models with osteosarcoma showed lytic intra-osseous lesions and periosteal reactive bone formation with deteriorated organization and directionality [26]. POEMS syndrome patients commonly present localized sclerotic bone lesions. We have conducted HR-pQCT for patients with newly diagnosed
POEMS syndrome, and found decreased vBMD in the cortex and normal $v B M D$ in the trabeculae, resulting from the combined effects of increased trabecular number and decreased trabecular thickness (unpublished data).

Interestingly, the occurrence of bone lesion does not always match the clinical symptoms of bone pain. Although 8 of all 13 patients showed marked aberrant bone lesion in HR-pQCT images (Fig. 1), only two of them presented clinical bone pain (LJ023 and LJ045). This finding indicates that the involvement of the skeletal system is common but insidious in the onset of the disease. Similarly, in another ECD cohort reported by Haroche and colleagues, skeletal involvement was found in almost all 11 ECD patients but only $50 \%$ of them suffered from bone pain [27].

There are also limitations in this study. First, this is a single center study, which may limit the generalizability of our findings. Second, HR-pQCT can only image peripheral skeletal sites, and was not fit for patients with bone lesions not close enough to the end-plate of radius and tibia. Third, we only repeated HR-pQCT in one patient's follow-up, which did not show significant changes in quantitative assessment (Table 3). A longer follow-up and repeated HR-pQCT in more ECD patients may identify the restoration of bone lesions and the effect of IFN- $\alpha$ on bone remodeling.

\section{Conclusions}

In conclusion, we studied the bone microarchitecture in 13 ECD patients using HR-pQCT imaging. Trabecular number, thickness and volumetric bone mineral density 
were significantly higher in ECD patients. Remarkable heterogeneity in bone microarchitecture was found in ECD patients, ranging from apparent normal structure, scattered thickening of trabecula to homogenous consolidation. The application of HR-pQCT may help to reveal the bone microarchitecture of ECD, and the nature of bone lesions in the disease.

\section{Supplementary information}

Supplementary information accompanies this paper at https://doi.org/10. 1186/s13023-020-01518-1.

\section{Additional file 1.}

\section{Abbreviations \\ ECD: Erdheim-Chester Disease; CNS: central nervous system; PET-CT: positron emission tomography-computed tomography; CT: computed tomography; MRI: magnetic resonance imaging; HR-pQCT: high-resolution peripheral quantitative computed tomography; $v B M D$ : volumetric bone mineral density; DXA: dual-energy X-ray absorptiometry; MGUS: monoclonal gammopathy of undetermined significance; GAMLSS: generalized additive models for location, scale, and shape; LCH: Langerhans cell histiocytosis; \\ ADO: autosomal dominant osteopetrosis}

\section{Acknowledgements}

We acknowledge all participants for their collaboration in the study.

\section{Authors' contributions}

Study design: XC, DZ, JL and WX. Study conduct: TH. Data collection: TH, NN FW, HM, HZ, CL, FY. Data analysis: TH and LC. Data interpretation: TH, LC, NN, FW. Drafting manuscript: TH and LC. Revising manuscript content: $X C, J$ and WX. Approving final version of manuscript: TH, LC, NN, FW, HM, HZ, XG, CL, $F Y, Y J, O W, M L, X X, D Z, J L, X C$, and $W X$. TH takes responsibility for the integrity of the data analysis.

\section{Funding}

This study was supported by grants from Institutional research funding provided by the Non-profit Central Research Institute Fund of the Chinese Academy of Medical Sciences (2019-RC-HL-001, for XC), the CAMS Innovation Fund for Medical Sciences (Grant No. 2016-12 M-1-002, for JL) and The National Key Research and Development Program of China (Grant No. 2016YFC0901503, for JL), National Natural Science Foundation of China (No. 81070687, 81170805 and 81670714, For WX), Beijing Natural Science Foundation (No. 7121012, for WX), National Key Program of Clinical Science (WBYZ2011-873, for WX), Collaborative Innovation Team Project of Medical and Health Science and Technology Innovation Project of Chinese Academy of Medical Sciences (No.2016-I2M-3-003, for WX), China Postdoctoral Science Foundation (2018 M631396, for LC).

\section{Availability of data and materials}

The datasets used and/or analysed during the current study are available from the corresponding author on reasonable request.

\section{Ethics approval and consent to participate}

Ethics approval was obtained for the study from the institutional board. All participants were informed both in person by $\mathrm{TH}$ and written, and informed consents were obtained. The study was performed in accordance with the ethical standards of the 1964 Declaration of Helsinki and its later amendments.

\section{Consent for publication}

Written informed consent for publication of their clinical details and/or clinical images was obtained from the patient/parent/guardian/ relative of the patient. A copy of the consent form is available for review by the Editor of this journal.

\section{Competing interests}

The authors declare that they have no competing interests.

\section{Author details}

${ }^{1}$ Department of Hematology, Peking Union Medical College Hospital, Chinese Academy of Medical Sciences, Beijing 100730, China. ²Department of Endocrinology, Key Laboratory of Endocrinology, Ministry of Health, Peking Union Medical College Hospital, Chinese Academy of Medical Sciences, Beijing 100730, China. ${ }^{3}$ Department of Nuclear Medicine, Peking Union Medical College Hospital, Chinese Academy of Medical Sciences, Beijing 100730, China. ${ }^{4}$ Department of Radiology, Peking Union Medical College Hospital, Chinese Academy of Medical Sciences, Beijing 100730, China.

Received: 20 February 2020 Accepted: 24 August 2020

Published online: 04 September 2020

\section{References}

1. Garcia-Gomez FJ, Acevedo-Banez I, Martinez-Castillo R, Tirado-Hospital JL, Cuenca-Cuenca Jl, Pachon-Garrudo VM, et al. The role of 18FDG, 18FDOPA $\mathrm{PET} / \mathrm{CT}$ and $99 \mathrm{mTc}$ bone scintigraphy imaging in Erdheim-Chester disease. Eur J Radiol. 2015;84(8):1586-92.

2. Cavalli G, Guglielmi B, Berti A, Campochiaro C, Sabbadini MG, Dagna L. The multifaceted clinical presentations and manifestations of Erdheim-Chester disease: comprehensive review of the literature and of 10 new cases. Ann Rheum Dis. 2013;72(10):1691-5.

3. Haroche J, Cohen-Aubart F, Amoura Z. Erdheim-Chester disease. Blood. 2020;135(16):1311-8.

4. Emile JF, Abla O, Fraitag S, Horne A, Haroche J, Donadieu J, et al. Revised classification of histiocytoses and neoplasms of the macrophage-dendritic cell lineages. Blood. 2016;127(22):2672-81.

5. Cao XX, Niu N, Sun J, Cai H, Wang FD, Wang YN, et al. Clinical and positron emission tomography responses to long-term high-dose interferon-alpha treatment among patients with Erdheim-Chester disease. Orphanet J Rare Diseases. 2019;14(1):11.

6. Haroche J, Cohen-Aubart F, Emile JF, Maksud P, Drier A, Toledano D, et al. Reproducible and sustained efficacy of targeted therapy with vemurafenib in patients with BRAF(V600E)-mutated Erdheim-Chester disease. J Clin Oncol. 2015:33(5):411-8

7. Niu N, Cao X, Cui R. A unique case of Erdheim-Chester disease with cervical and lumbosacral nerve involvement: FDG PET/CT finding. Clin Nucl Med. 2016:41(11):881-3.

8. Van Keerberghen CA, Harrouk A, Leone L. A new role for fluorine-18fluorodeoxyglucose positron-emission tomography/computed tomography in Erdheim-Chester disease. World J Nuclear Med. 2019;18(2):201-3.

9. Cao XX, Niu N, Sun J, Zhou DB, Li J. Efficacy of intermediate-dose cytarabine in central nervous system-relapsed wild-type BRAF Erdheim-Chester disease. Ann Hematol. 2018:97(1):185-7.

10. Hung WW, Zhu TY, Cheung WH, Fong TN, Yu FW, Hung LK, et al. Agerelated differences in volumetric bone mineral density, microarchitecture, and bone strength of distal radius and tibia in Chinese women: a highresolution PQCT reference database study. Osteoporos Int. 2015;26(6):1691703.

11. Chiang CY, Zebaze R, Wang XF, Ghasem-Zadeh A, Zajac JD, Seeman E. Cortical matrix mineral density measured noninvasively in pre- and postmenopausal women and a woman with vitamin D-dependent rickets. J Bone Mineral Res. 2018:33(7):1312-7.

12. Zysset P, Qin L, Lang T, Khosla S, Leslie WD, Shepherd JA, et al. Clinical use of quantitative computed tomography-based finite element analysis of the hip and spine in the Management of Osteoporosis in adults: the 2015 ISCD official positions-part II. J Clin Densitometry. 2015;18(3):359-92.

13. Rupp T, Butscheidt S, Vettorazzi E, Oheim R, Barvencik F, Amling M, et al. High FGF23 levels are associated with impaired trabecular bone microarchitecture in patients with osteoporosis. Osteoporos Int. 2019;30(8): 1655-62.

14. Rolvien T, Kornak U, Schinke T, Amling M, Oheim R. A novel FAM20C mutation causing hypophosphatemic osteomalacia with osteosclerosis (mild Raine syndrome) in an elderly man with spontaneous osteonecrosis of the knee. Osteoporos Int. 2019;30(3):685-9.

15. Ng AC, Khosla S, Charatcharoenwitthaya N, Kumar SK, Achenbach SJ, Holets $\mathrm{MF}$, et al. Bone microstructural changes revealed by high-resolution 
peripheral quantitative computed tomography imaging and elevated DKK1 and MIP-1alpha levels in patients with MGUS. Blood. 2011;118(25):6529-34.

16. Pialat JB, Burghardt AJ, Sode M, Link TM, Majumdar S. Visual grading of motion induced image degradation in high resolution peripheral computed tomography: impact of image quality on measures of bone density and micro-architecture. Bone. 2012;50(1):111-8.

17. $R$ Core Team. R: A language and environment for statistical computing. $R$ Foundation for Statistical Computing, Vienna, Austria. URL https://www.rproject.org/. 2019

18. Coupe C. Modeling linguistic variables with regression models: addressing non-Gaussian distributions, non-independent observations, and non-linear predictors with random effects and generalized additive models for location, scale, and shape. Front Psychol. 2018:9:513.

19. Yu F. Age-, site- and gender-specific reference centile curves and normative data for HRpQCT-derived bone structural parameters in Chinese mainland population: Peking union medical college; 2019.

20. Haroche J, Charlotte F, Arnaud L, von Deimling A, Helias-Rodzewicz Z, Hervier B, et al. High prevalence of BRAF V600E mutations in ErdheimChester disease but not in other non-Langerhans cell histiocytoses. Blood. 2012;120(13):2700-3.

21. Chinchilla EA, Gourde MP, Turcotte K, Mathieu S, Amin-Hashem M. Case of Erdheim-Chester presenting with xanthelasma-like eruption and osteolytic bone lesions: A case report. SAGE open medical case reports. 2019;7: $2050313 \times 19845217$

22. Ozkaya N, Rosenblum MK, Durham BH, Pichardo JD, Abdel-Wahab O, Hameed MR, et al. The histopathology of Erdheim-Chester disease: a comprehensive review of a molecularly characterized cohort. Modern Pathol. 2018;31(4):581-97.

23. Dion E, Graef C, Miquel A, Haroche J, Wechsler B, Amoura Z, et al. Bone involvement in Erdheim-Chester disease: imaging findings including periostitis and partial epiphyseal involvement. Radiology. 2006;238(2):632-9.

24. Arruda M, Coelho MC, Moraes AB, de Paula P-NF, Madeira M, Farias ML, et al. Bone mineral density and microarchitecture in patients with autosomal dominant Osteopetrosis: a report of two cases. J Bone Mineral Res. 2016;31(3):657-62.

25. Rolvien T, Krause M, Zustin J, Yastrebov O, Oheim R, Barvencik F, et al. Intraarticular osteoid osteoma accompanied by extensive bone marrow edema. A clinical and micro-morphological analysis. J Bone Oncol. 2019;18:100256.

26. Cole HA, Ohba T, Ichikawa J, Nyman JS, Cates JM, Haro H, et al. Microcomputed tomography derived anisotropy detects tumor provoked deviations in bone in an orthotopic osteosarcoma murine model. PLoS One. 2014;9(6):e97381.

27. Haroche J, Arnaud L, Cohen-Aubart F, Hervier B, Charlotte F, Emile JF, et al. Erdheim-Chester disease. Rheum Dis Clin N Am. 2013;39(2):299-311.

\section{Publisher's Note}

Springer Nature remains neutral with regard to jurisdictional claims in published maps and institutional affiliations.

Ready to submit your research? Choose BMC and benefit from:

- fast, convenient online submission

- thorough peer review by experienced researchers in your field

- rapid publication on acceptance

- support for research data, including large and complex data types

- gold Open Access which fosters wider collaboration and increased citations

- maximum visibility for your research: over $100 \mathrm{M}$ website views per year

At BMC, research is always in progress.

Learn more biomedcentral.com/submissions 